\title{
Nitrogen and phosphorus associating with different size suspended solids in roof and road runoff in Beijing, China
}

\author{
Junliang $\mathrm{Wu}^{1,2,3} \cdot$ Yufen $\operatorname{Ren}^{2} \cdot$ Xuemei Wang ${ }^{1,3}$. \\ Xiaoke Wang ${ }^{2} \cdot$ Liding Chen ${ }^{2} \cdot$ Gangcai Liu ${ }^{1}$
}

Received: 5 November 2014 / Accepted: 18 May 2015 /Published online: 4 June 2015

(C) Springer-Verlag Berlin Heidelberg 2015

\begin{abstract}
Roofs and roads, accounting for a large portion of the urban impervious land surface, have contributed significantly to urban nonpoint pollution. In this study, in Beijing, China, roof and road runoff are sampled to measure the suspended solids (SS), nitrogen $(\mathrm{N})$, and phosphorus $(\mathrm{P})$ contained in particles with different sizes. The SS content in the road runoff $(151.59 \mathrm{mg} / \mathrm{L})$ was sevenfold that in the roof runoff $(21.13 \mathrm{mg} / \mathrm{L}, p<0.05)$. The SS contained more coarse particulates in the roof runoff than in road runoff. The small particulates in the range of $0.45-50 \mu \mathrm{m}$ consisted of $59 \% \mathrm{SS}$ in the roof runoff and $94 \% \mathrm{SS}$ in the road runoff. P was mainly attached to particle sizes of $10-50 \mu \mathrm{m}$ in the roof $(73 \%)$ and road (48 \%) runoffs, while $\mathrm{N}$ was mainly in a dissolved phase state in both runoffs. So, the different
\end{abstract}

Responsible editor: Philippe Garrigues

Electronic supplementary material The online version of this article (doi:10.1007/s11356-015-4743-9) contains supplementary material, which is available to authorized users.

Yufen Ren

yfren@rcees.ac.cn

Gangcai Liu

liugc@imde.ac.cn

1 Key Laboratory of Mountain Hazards and Earth Surface Processes, Chinese Academy of Sciences, Institute of Mountain Hazards and Environment, Chinese Academy of Sciences and Ministry of Water Resources, No. 9, Block 4, Renminnanlu Road, P.O. Box: 417, Chengdu 610041, China

2 State Key Laboratory of Urban and Regional Ecology, Research Center for Eco-Environmental Sciences, Chinese Academy of Sciences, P.O. Box: 2871, Beijing 100085, China

3 University of Chinese Academy of Sciences, Beijing 100049, China associations of $\mathrm{N}$ and $\mathrm{P}$ raise a challenge in preventing stormwater pollution in urban environments.

Keywords Roof runoff · Road runoff · Suspended solid · Nitrogen $\cdot$ Phosphorus

\section{Introduction}

Previous investigations have suggested that suspended solid (SS) associated pollutions, such as metal (Zhao et al. 2010), nutrients (Vaze and Chiew 2004), and polycyclic aromatic hydrocarbons (PAHs) (Aryal et al. 2005; Fang et al. 2004; Ha et al. 2012), have become one of the main components of nonpoint pollution in urban environments. The finer particles especially have the highest adsorption capacities due to their larger specific surface area (Herngren et al. 2005) and are relatively difficult and costly to remove. So, it is necessary to investigate SS in urban runoff in order to understand their production and transportation in the drainage system and thus develop appropriate strategies to minimize their impacts on the urban aquatic environment.

Although nutrients ( $\mathrm{N}$ and $\mathrm{P}$ ) as the most common type of pollutants have been investigated since the late twentieth century, water quality is still degraded primarily by $\mathrm{N}$ and $\mathrm{P}$ pollutants. With the effective controlling of point sources, diffusive $\mathrm{N}$ and $\mathrm{P}$ pollution, which are generally related to stormwater runoff, have become a difficult challenge for clear water (Conley et al. 2009; Lee and Bang 2000; Novotny and Witte 1997). In urban environments, $\mathrm{N}$ and $\mathrm{P}$ pollutions are still a very serious problem. Major sources of $\mathrm{N}$ and $\mathrm{P}$ pollutants are stormwater runoff, especially when $\mathrm{N}$ and $\mathrm{P}$ pollutants from households and industries are treated in wastewater treatment facilities. Therefore, investigating the $\mathrm{N}$ and $\mathrm{P}$ pollution from roof and road runoff are very meaningful for improving 
urban water quality. Much of the research has indicated that most N (at least 50-60\%) are particulate bound in urban runoff (Gastaldini and Silva 2013; Vaze and Chiew 2004). Though this is generally believed to be true, there is also some contradictory evidence to show $\mathrm{N}$ in a dissolved phase state in urban stormwater runoff (Gan et al. 2008; Han et al. 2006; Miguntanna et al. 2013; Taylor et al. 2005). Therefore, it is necessary to reconsider $\mathrm{N}$ pollution wash-off phase in urban roof and road runoff. Moreover, $\mathrm{P}$ has been predominantly found in its particle form in urban road runoff (Zhou et al. 2013); however, to our knowledge, there have been few investigations to determine $\mathrm{P}$ particle size distribution in urban roof runoff (Taylor et al. 2005).

Knowledge of the occurrence of pollution and its attribution to the particulate or dissolved phase is crucial for the development of effective treatment systems and reducing the costs associated with monitoring (Brezonik and Stadelmann 2002; Sansalone and Buchberger 1995; Han et al. 2006). Some commonly used high-frequency measurements have the powerful potential to be used as surrogates to estimate other properties, such as constituent concentrations. Gan et al. (2008) showed that SS and EC were chosen as indications of their relative proportions of dissolved or particulate forms in the runoff, respectively. However, surrogate indicators for determining other pollutant loads were found to be inappropriate in the runoff (Liu et al. 2013). How extent is it to represent the pollution of the $\mathrm{N}$ and $\mathrm{P}$ in the runoff with TSS and EC indices? This paper reports the concentrations of TSS, EC, N, and $\mathrm{P}$ in the roof and road storm water runoff, and the correlations among pollutants were examined. The information gained from this correlation analysis may be used to explore the feasibility of EC and TSS surrogate of nutrients in the runoff.

Roof and road runoffs have been identified in urbandominated watersheds as potential and important sources of nonpoint pollution, contributing to the degradation of water quality. Since the 1980s, investigations into stormwater pollution from roofs and roads have been conducted widely in some countries, such as USA (Sansalone and Buchberger 1997; Pitte and Morquecho 2005), China (Ren et al. 2008; Huang et al. 2007), Korea (Lee et al. 2012), and France (Gromaire et al. 1999). They have revealed that discrepancies in pollutant concentrations exist between roof and road runoffs. However, little knowledge is available concerning the discrepancies in the nutrients ( $\mathrm{N}$ and $\mathrm{P}$ ) wash-off phase state between them.

Beijing, the capital of China, currently faces a serious problem of environment pollution. About $60 \%$ of the urban water environment has been seriously polluted by eutrophication of the rivers, lakes, and reservoirs of Beijing (Du et al. 2005; Jing et al. 2008). Rainfall has influenced the nutrients of the rivers in the Yongding Diversion Channel (Wang et al. 2014), and wet $\mathrm{N}$ deposition is extremely serious, at approximately $30.6 \mathrm{~N} \mathrm{ha}^{-1}$ year $^{-1}$ (Liu et al. 2006), thus indicating that runoff pollution is important to managing the quality of receiving waters for Beijing. However, considerable data exist on the concentrations of $\mathrm{N}$ and $\mathrm{P}$ in urban runoff (Gilbert and Clausen 2006; Li et al. 2007; Roberts et al. 2009; Taylor et al. 2005) and on the buildup of nutrients (Vaze and Chiew 2002, 2004); knowledge regarding the basic their wash-off state in urban runoff currently remains limited, especially for Beijing.

This study investigates SS, N, and P concentrations in roof and road runoffs in Beijing, China. It aims to (1) assess the SS, $\mathrm{N}$, and $\mathrm{P}$ pollution in roof and road runoffs and (2) analyze $\mathrm{N}$ and $\mathrm{P}$ concentration associations with difference particle sizes in roof and road runoffs.

\section{Material and methods}

\section{Description of study catchment}

The sampling site is located in Beijing, the capital of China. The climate of Beijing is classified as subhumid continental monsoon. The average annual rainfall is $548.9 \mathrm{~mm}$, approximately $80 \%$ of which occurs in the summer and autumn. The average annual temperatures range from 11.0 to $14.5^{\circ} \mathrm{C}$, the highest temperature reaching $41.9^{\circ} \mathrm{C}$, the lowest temperature to $-17.0^{\circ} \mathrm{C}$ (BMBS 2014).

The roof runoff study was carried out on the campus of the Research Centre for Eco-Environmental Sciences (RCEES), located in the northern area of Beijing (Fig. 1). The campus is surrounded by a residential and educational area without any nearby industrial activities. Roof runoff samples were collected from two roofs representative of study area construction (i.e., concrete and asphalt) for storm water runoff quality. The concreter roof building was completed in 2012, and the asphalt roofing was repaved in 2013.

Road runoffs were sampled at rainwater drainage outlets at six sites below an overpass of the roads (Fig. 1). These ring roads have three traffic lanes plus one emergency parking lane in each direction, covered by asphalt with a gradient of 5$10 \%$, and are cleared daily by auto sweepers, and the load of average annual daily traffic (AADT) is greater than 20,000 vehicles per day.

\section{Sample collection}

Rainfall was measured on the rooftop of a building at RCEES (Table 1). Composite runoff samples continuously accumulate in a fixed fraction of the runoff proportional to the flow rate for 


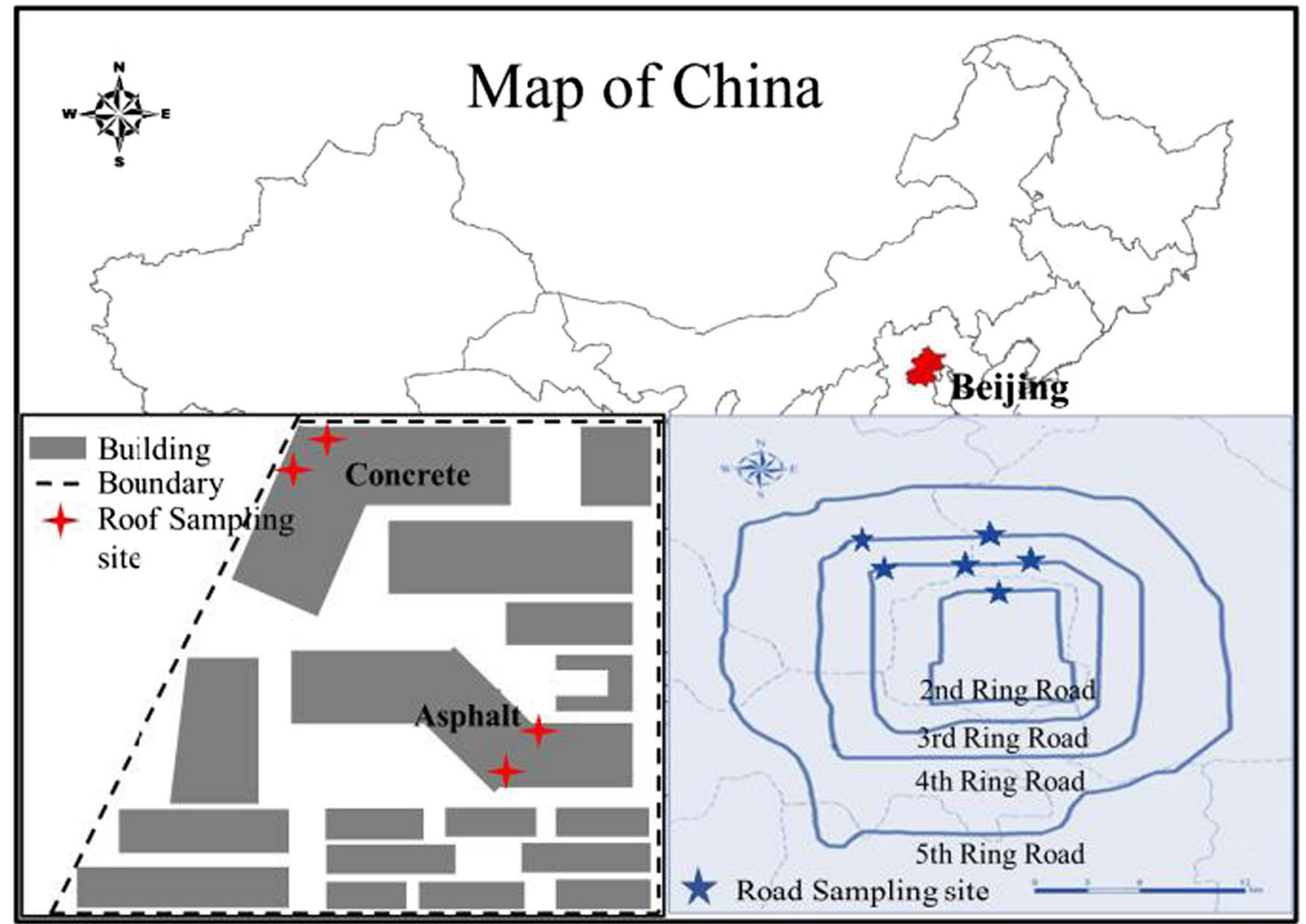

Fig. 1 Map of roof runoff and expressway road runoff sampling sites

determination of the pollution average characteristics of the runoff (Clark et al. 1981; Ren et al. 2008). Roof runoff sampling was carried out from the outlet of the building drainpipe into a polyethylene container. Road runoff was strained through a piece of gauze to extract debris and then collected by diverting part of the flow from the final point of the road drain pipes into a 120-L polyethylene container (Hou 2012). We collected 25 samples from the roof and 42 from the road runoff from June to September 2013. All samples were surveyed for the relationship between the average EC and TSS and nutrients in the roof and road runoff, respectively. Twentysix road runoff samples and six roof runoff samples were used to analyze the size SS distribution in the different sizes, and eight road runoff samples and four roof runoff samples were used to analyze the $\mathrm{N}$ and $\mathrm{P}$ distribution in the different sizes of SS from six rain events between 15 July and 28 August.

\section{Particle size fractioning methods}

The size distribution of runoff particles was determined using a set of stainless steel sieves $(200,100$, and $50 \mu \mathrm{m})$ and filter papers of 10 and $0.45 \mu \mathrm{m}$. Particles were fractioned into six sizes, with respective diameters of $<0.45,0.45-10,10-50$, $50-100,100-200$, and $>200 \mu \mathrm{m}$. Then, the different sized particles were dissolved separately in $50 \mathrm{~mL}$ of distilled water and tested for total phosphorus (TP) and total nitrogen (TN).

\section{Sample analysis}

Water quality parameters, including the electrical conductivity (EC), total suspended solids (TSS), TN, and TP were analyzed by methods recommended by the State Environmental Protection Agency of China (SEPA 1989). Briefly, the TSS was
Table 1 Characteristics of rainfall events and antecedent dry weather period conditions (ADWP) in the RCEES catchment

\begin{tabular}{lcccc}
\hline Rainfall date & Rainfall $(\mathrm{mm})$ & Duration $(\mathrm{h})$ & Average intensity $(\mathrm{mm} / \mathrm{h})$ & ADWP (days) \\
\hline 15 July & 57.6 & 23.0 & 2.5 & 4 \\
30 July & 32.4 & 23.0 & 1.4 & 3 \\
1 August & 20.0 & 1.8 & 11.1 & 0 \\
8 August & 6.9 & 16.0 & 0.4 & 3 \\
11 August & 70.7 & 4.1 & 17.2 & 3 \\
28 August & 20.0 & 6.5 & 3.1 & 8 \\
\hline
\end{tabular}


measured by filtering, drying, and weighing (GB11901-89). The particle size distribution of the SS in the runoff water was measured using a Mastersizer 2000 laser particle size analyzer (Malvern Instruments, UK). TN was analyzed by the alkaline potassium persulfate digestion-UV spectrophotometric method (GB11894-89) and TP by the persulfate digestion spectrophotometric method (GB11893-89).

\section{Data statistics}

The difference in pollutant concentration between roof and road runoffs was tested by one-way analysis of variance and, in the case of significance, differentiated by the Dunn LSD test. The correlation of $\mathrm{N}$ and $\mathrm{P}$ concentrations with $\mathrm{EC}$ and TSS was analyzed by linear and logarithmic regression, respectively. EC and TSS were the independent variables. All statistical analyses were performed using SPSS 17.0 (SPSS Inc. USA) and Excel 2010 (Microsoft, USA).

\section{Results and discussions}

\section{Water quality of the runoff}

According to the Environmental Quality Standard for Surface Water in China, the mean concentration of TP $(0.32 \mathrm{mg} / \mathrm{L})$ in roof runoff and $\mathrm{TN}$ in roof $(13.66 \mathrm{mg} / \mathrm{L})$ and road $(12.96 \mathrm{mg} /$ L) runoffs exceeds the Grade IV values for TP and TN (GB3838-2002; Fig. 2). The SS content in road runoff $(151.59 \mathrm{mg} / \mathrm{L})$ was sevenfold that in roof runoff $(21.13 \mathrm{mg} /$
$\mathrm{L}, p<0.05$ ), while for other runoff quality parameters (EC, $\mathrm{TN}, \mathrm{TP})$, there were no significant differences between the roof and road runoffs.

$\mathrm{N}, \mathrm{P}$, and SS are the major pollutants in the runoff from roofs and road surfaces in the Beijing urban area because their concentration has exceeded grade IV of the Surface Water Quality Standard (Fig. 2). So, storm water runoff from the roofs and road surfaces cannot be directly reused as city municipal and domestic water or discharged into urban water bodies. Treatment processes are necessary.

Significant differences in SS concentrations occur between different underlying surface runoffs. The average concentrations of road runoff SS are greater than roof runoff SS, and the SS concentration in road runoff has increased sevenfold over those in roof runoff $(p<0.05)$. This can contribute to the complexity of the source of the SS in road runoff. Except for atmospheric deposition, the sources of SS in road runoff are complicated by land-use, traffic volume, road seeping, and so on (Opher and Friedler 2010).

\section{Particle size distribution of SS in the runoffs}

Nearly a half of the SS were particles in the range of 10 $50 \mu \mathrm{m}, 46 \%$ in the roof runoff, and $48 \%$ in the road runoff. Thirteen percent of particles in the roof runoff and $46 \%$ in the road runoff (Fig. 3) were of less than $10 \mu \mathrm{m}$. Particles larger than $50 \mu \mathrm{m}$ comprised $41 \%$ of the roof runoff and $6 \%$ of road runoff. This implies that coarser particles are contained in roof runoff than in road runoff.
Fig. 2 Water quality of the roof runoff and road runoff. Pollution emission values of Class IV, Environmental Quality Standard for Surface Water in China (GB3838-2002) (asterisk)
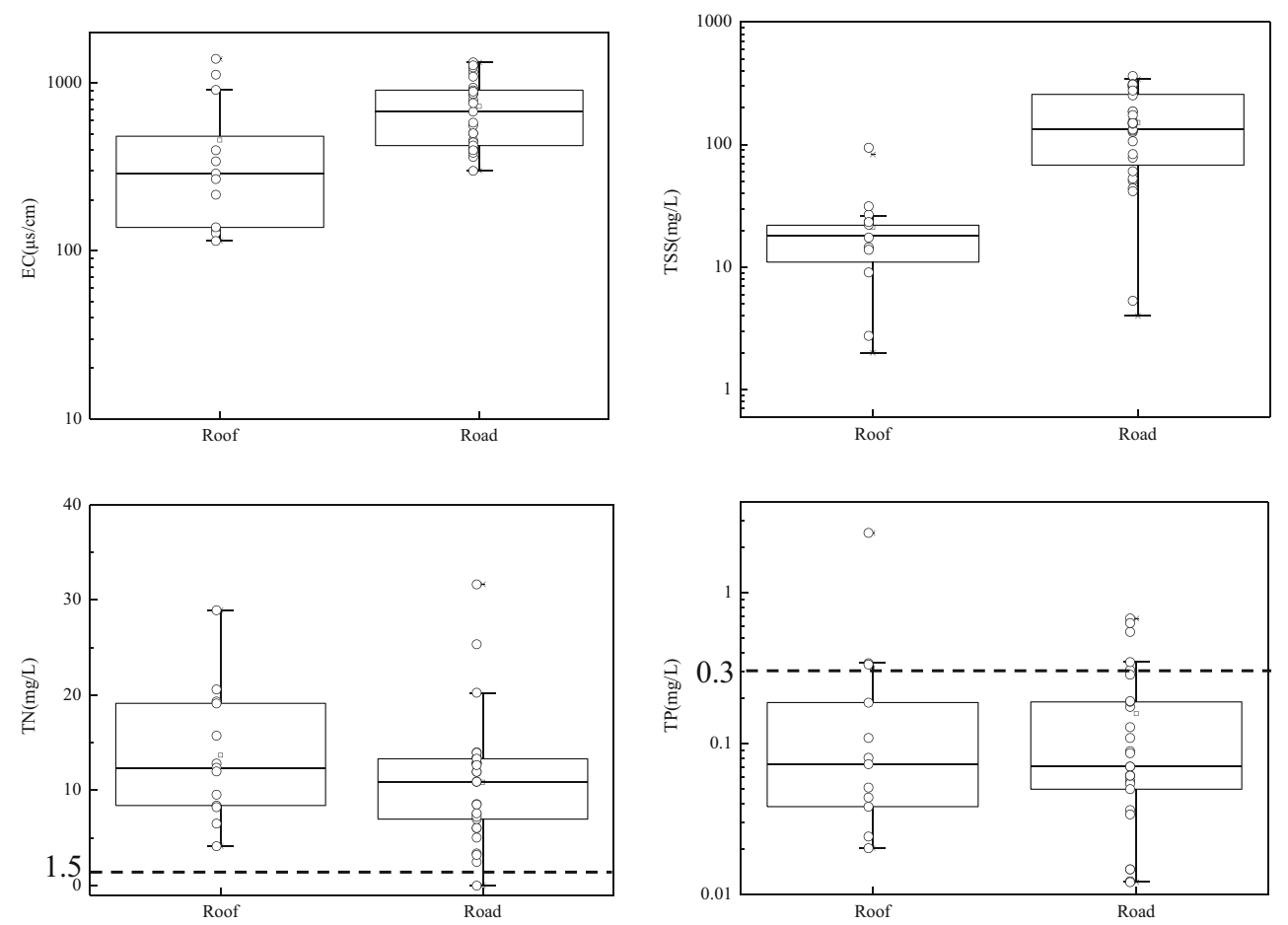
Fig. 3 Particle size distribution of SS in the roof runoff (a) and road runoff $(\mathbf{b})$
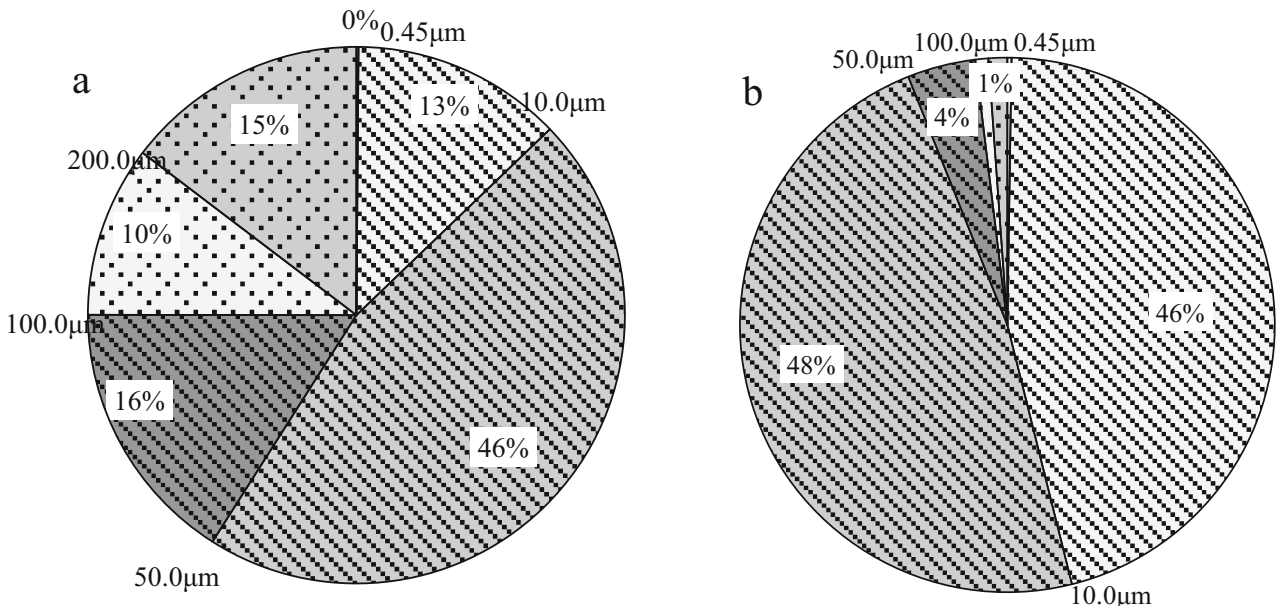

Particle size influences the adsorption capacity and transport capability of particulates. The smaller particles are more likely to be washed away by urban runoff and pose a greater risk to the receiving water body, since they have higher mobility, greater pollution concentrations, and less settling ability (Aryal et al. 2005; Murakami et al. 2005). Fifty-nine percent of SS were in the range $0.45-50 \mu \mathrm{m}$ in the roof runoff, while $94 \%$ were in the range of $0.45-50 \mu \mathrm{m}$ in the road runoff. The different SS distribution between roof and road runoffs may be attributed to the road sweeper, which might be removing coarser particles, and its low efficiency in removing fine material $(<50 \mu \mathrm{m})$ (Furumai et al. 2002; Zhao et al. 2010). In addition, high traffic intensity could produce finer particles in the road runoff by friction, but there are few anthropogenic activities taking place on the roofs. Thus, there are more fine particles in the road runoff than the roof runoff. In other words, the concentration and particle size distribution of particles are influenced by the underlying surface in urban stormwater, which should be taken into account in the design of water quality mitigation strategies. Measures instigated to reduce the impact of particles in the roof runoff may prove to be inefficient in removing the particles in the road runoff. Therefore, different mitigation strategies may be employed to remove SS in the roof runoff and road runoff.

Our results (Fig. 4) are consistent with those of previous studies investigating particle distribution in urban runoff (Anta et al. 2006; Goonetilleke et al. 2009; Sansalone and Kim 2008): Particle size in urban runoff was predominantly less than $100 \mu \mathrm{m}$. However, the particles are smaller in the Beijing runoff compared with other research results. Taking the particles in the road runoff for example, the results of a study by Roger et al. (1998) showed that about $75 \%$ of the solid matter was in the form of particles smaller than $50 \mathrm{~mm}$, while in the Beijing road runoff, $94 \%$ was in the range of $0.45-50 \mu \mathrm{m}$. Therefore, in the context of Beijing stormwater quality management, mitigation strategies could be employed to effectively remove particles in the $0.45-50-\mu \mathrm{m}$ size fraction in the runoff.

\section{$\mathrm{N}$ and $\mathrm{P}$ content associated with different sizes of suspended particles}

Most of the TN was in the dissolved phase in the roof $(94.3 \%)$ and road $(88.9 \%$ ) runoffs (less than $0.45 \mu \mathrm{m}$ ). Consequently, 4.5 and $9.3 \%$ of the TN were associated with particles of 10 $50 \mu \mathrm{m}$ (Fig. 5a). TP was predominantly associated with particles greater than $0.45 \mu \mathrm{m}$ in the roof $(57.5 \%)$ and road (84.6\%) runoffs, of which 47.9 and $72.9 \%$ of the TP were associated with particles of $10-50 \mu \mathrm{m}$ in the roof and road runoffs, respectively (Fig. 5b).

In our study, $80-95 \%$ of the TN are dissolved in the runoff $(<0.45 \mu \mathrm{m})$. The nitrogen compounds are in dissolved form in the biogeochemical process, which also determines that dissolved nitrogen is the main method of migration in the runoff. Some research has indicated that most of the $\mathrm{N}$ in roof and road runoffs are particulate bound (Gastaldini and Silva 2013; Vaze and Chiew 2004), but our research demonstrates that $\mathrm{N}$ was mainly transported in dissolved form or soluble species in urban runoff. The differences can be attributed to the $\mathrm{N}$ in the roof and road runoffs of Beijing mainly coming from wet depositions (Hou 2012).

TP of 70-90\% was found to be associated with particles of less than $50 \mu \mathrm{m}$ in diameter (Fig. 5). Gastaldini and Silva (2013) surveys show that the size distribution of $\mathrm{P}$ was very similar. The TP is associated with the SS in a way that is based on the character of phosphorus in nature. The $\mathrm{P}$ compounds found on the surface of the Earth are not volatile (Correll 1998). Except for alkali metal phosphates, other phosphates are insoluble. It is not surprising that a large percentage of the total mass of $\mathrm{P}$ is associated with small particles. 
Fig. 4 Comparison of SS distributions in urban stormwater. The grains size, unit is $\mu \mathrm{m}$ (asterisk)

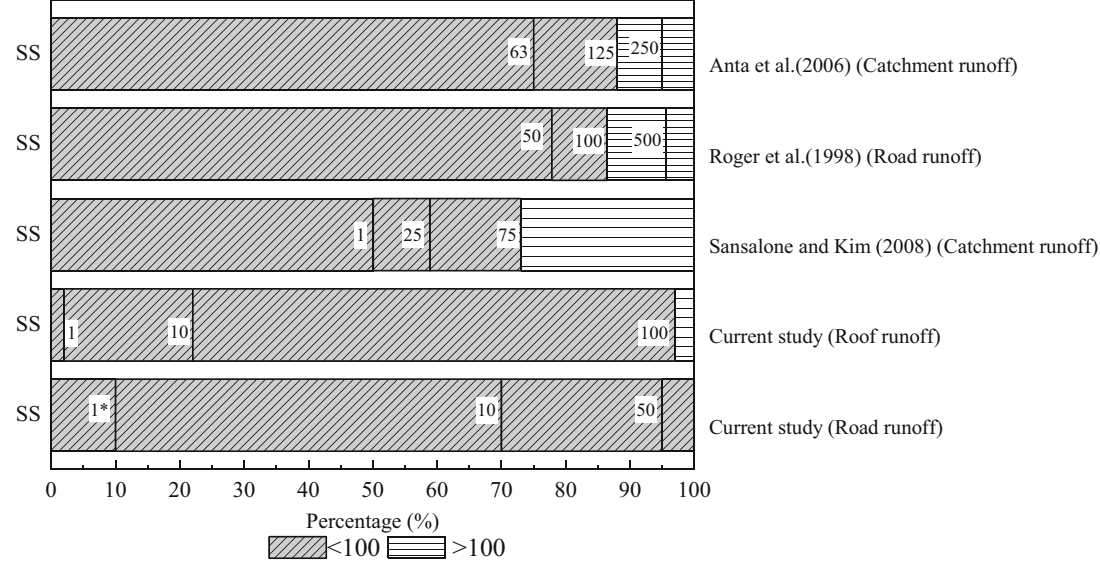

A small percentage of the total mass of $\mathrm{P}$ was detected in the dissolved fraction $(<0.45 \mu \mathrm{m})$ in the road runoff (only $15 \%$ ). However, $42 \%$ of $\mathrm{P}$ in the roof runoff was detected in the dissolved phase $(<0.45 \mu \mathrm{m})$. The reason maybe is that $\mathrm{P}$ originating from deposition is a small portion of the $\mathrm{P}$ in road runoff, and other sources contribute a significant amount of $\mathrm{P}$ (Opher and Friedler 2010).

\section{Correlations between N, P, SS, and EC}

TN was significantly related to EC (Fig. 6a) in both roof $\left(R^{2}=\right.$ $0.8017)$ and road $\left(R^{2}=0.7507\right)$ runoffs, and TP was significantly related to the TSS (Fig. 6b) in both roof $\left(R^{2}=0.8855\right)$ and $\operatorname{road}\left(R^{2}=0.8870\right)$ runoffs.

SS especially were chosen because they are a well-known surrogate for other common stormwater-associated pollutants including trace metals, chlorinated hydrocarbons, and PAHs, depending on the constituents' correlations (Maniquiz et al. 2009; Sansalone and Buchberger 1995; Schiff and Tiefenthaler 2011; Sheng et al.
2008). A strong correlation with SS together with a weak one with EC would reveal a large proportion of particulate forms, while the opposite situation would indicate that the constituent is mostly dissolved (Opher and Friedler 2010). The strong correlation of the $\mathrm{N}$ concentration with EC also shows that a large proportion of the $\mathrm{N}$ in the stormwater sample was dissolved. And, the strong relationship between TP and TSS and the weak one with EC in the runoff also showed that $\mathrm{P}$ is particle-bound in the roof and road runoffs in Beijing.

The information gained from this correlation analysis may assist transportation agencies in reducing the number of constituents that they are required to monitor. EC as a surrogate can explain approximately 80.17 and $75.07 \%$ of variation in EMCs of the $\mathrm{N}$ in the roof and road runoff, respectively, TSS as a surrogate can explain approximately 88.55 and $88.70 \%$ of variation in EMCs of the $\mathrm{P}$ in the roof and road runoff, respectively, and EC and TSS may appear to be a surrogate of dissolved $\mathrm{N}$ or particulate $\mathrm{P}$ in the runoff, respectively.
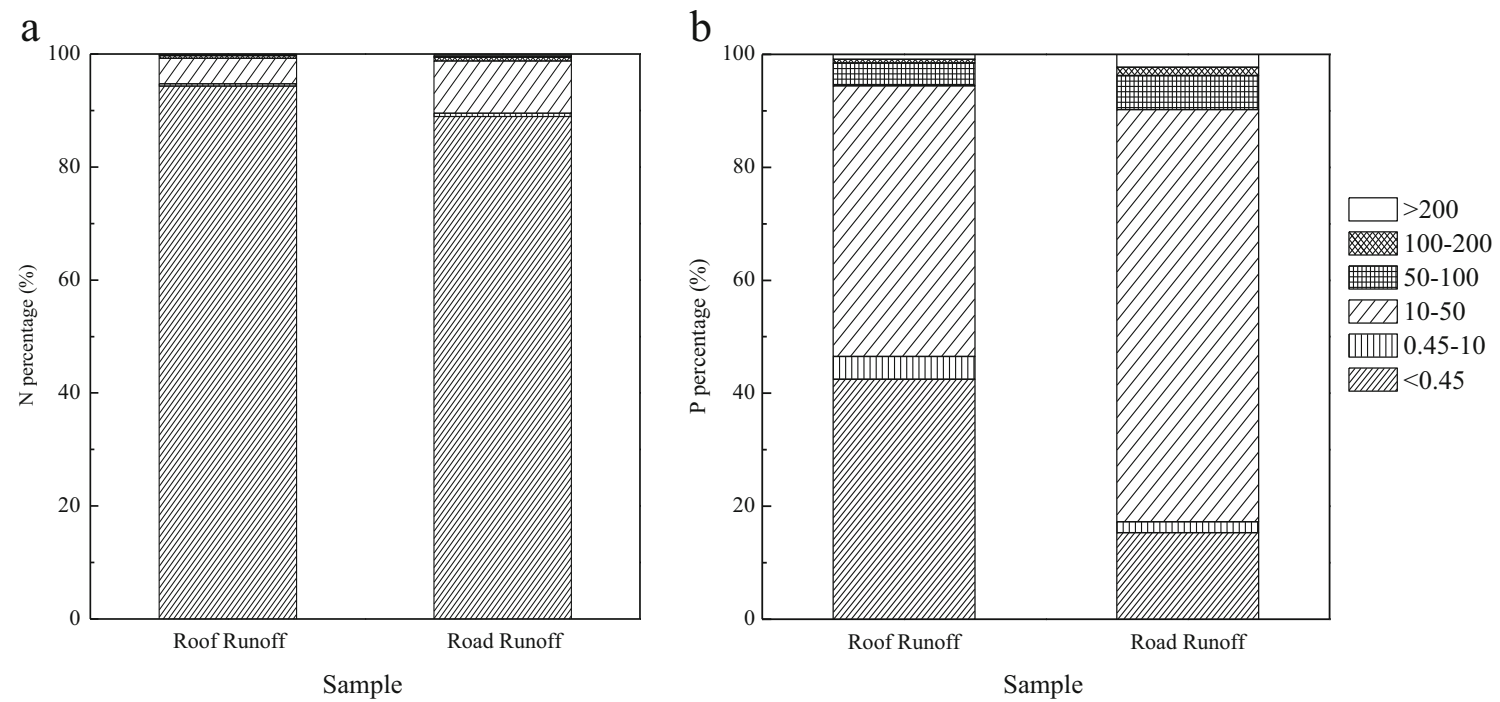

Fig. 5 Nutrient distributions by different particle sizes 
Fig. 6 Correlation of the concentrations of TN and TP to $\mathrm{EC}$ and TSS in the roof and road runoffs. Note the independent variables: EC and TSS
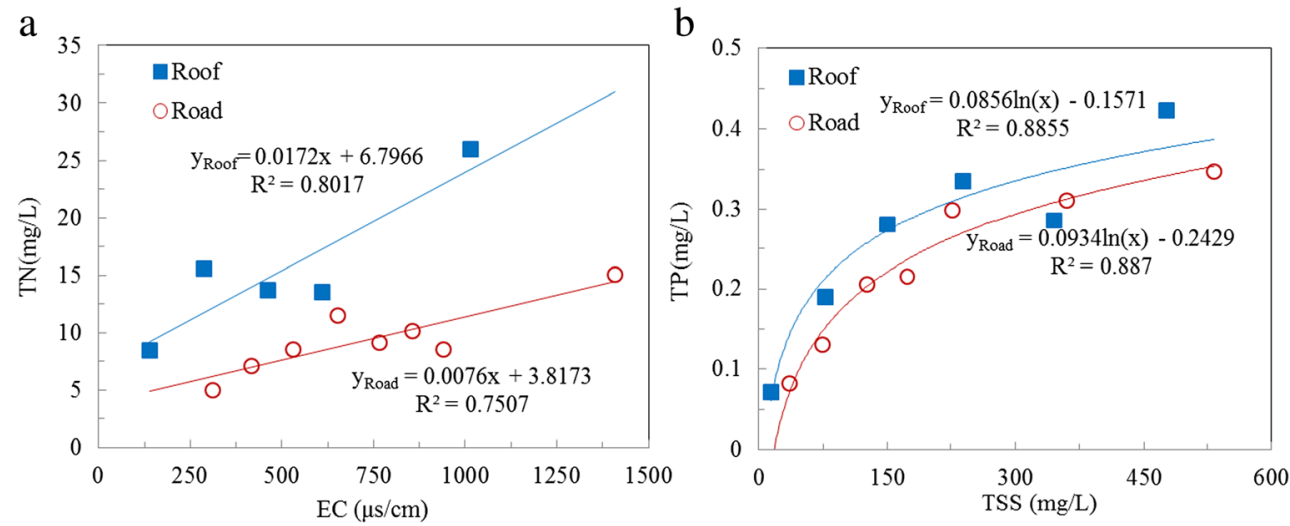

\section{Conclusion}

The significantly high SS, N, and P concentrations in roof and road runoffs indicated that they are the major pollutants of stormwater in the Beijing urban area. Therefore, roof and road runoffs are potentially pollution sources of the urban aquatic environment and should be controlled to improve urban water quality in Beijing.

In roof and road runoffs, $\mathrm{P}$ was transported mainly in particle association and $\mathrm{N}$ in a dissolved form. Different strategies should be applied to control $\mathrm{P}$ and $\mathrm{N}$ pollution to minimize the environmental impact of the urban runoff or to reuse urban runoff in water shortage regions. Our results suggested that reducing suspended substances (particles) could control $\mathrm{P}$ pollution and $\mathrm{N}$ is more difficult to control because most of it is dissolved in water.

The concentration and particle size distribution of particles are influenced by the underlying surface in urban storm water. Up to $94 \%$ of the total particle volume distribution was found in the fine particles $(0.45-50 \mu \mathrm{m})$ confirming high $\mathrm{P}$ concentrations in combination with these particles in the road runoff. Therefore, particles $0.45-50 \mu \mathrm{m}$ in size should be paid more attention to in the runoff quality management at road runoff. For roof runoff, $42 \%$ of $\mathrm{P}$ was detected in the dissolved phase, and particles larger than $50 \mu \mathrm{m}$ comprised $41 \%$, which should be considered together for more effective runoff quality management design.

EC and TSS appear to be a surrogate of dissolved (N) or particulate $(\mathrm{P})$ forms in monitoring the nutrient pollution in the urban runoff, respectively. The information gained from these correlation analyses may assist other researchers in evaluating and predicting the runoff water quality without collecting additional data, thereby reducing the monitoring costs.

Acknowledgments This study was supported in part by the State Key Program of National Natural Science of China (Grant No. 41230633 and 41030744).

\section{References}

Anta J, Pena E, Suárez J, Cagiao J (2006) A BMP selection process based on the granulometry of runoff solids in a separate urban catchment. Water SA 32(3):419-428

Aryal RK, Furumai H, Nakajima F, Boller M (2005) Dynamic behavior of fractional suspended solids and particle-bound polycyclic aromatic hydrocarbons in highway runoff. Water Res 39(20):5126-5134

Beijng Municipal Bureau of Statistics (BMBS) and NBS Survey Office in Beijing (NBSSOB). 2014 Beijing statistical yearbook [EB/OL]. China Statistics Press, Beijing, http://www.bjstats.gov.cn/nj/main/ 2014-tjnj/CH/content/mV91_0417.htm, 2014.09

Brezonik PL, Stadelmann TH (2002) Analysis and predictive models of stormwater runoff volumes, loads, and pollutant concentrations from watersheds in the Twin Cities metropolitan area, Minnesota, USA. Water Res 36:1743-1757

Clark DL, Asplund R, Ferguson J, Mar BW (1981) Composite sampling of highway runoff. J Environ Eng Div 107(EE5):1067-1081, ASCE

Conley DJ, Paerl HW, Howarth RW, Boesch DF, Seitzinger SP, Havens KE, Lancelot C, Linkens GE (2009) Controlling eutrophication: nitrogen and phosphorus. Science 323:1014-1015

Correll DL (1998) The role of phosphorus in the eutrophication of receiving waters: a review. J Environ Qual 27:261-266

Du GS, Wu YM, Yang ZS, Wu DW, Liu J (2005) Analysis of water quality on urban rivers and lakes in Beijing. J Lake Sci 17(4):373377 (in Chinese)

Fang GC, Chang KF, Lu CS, Bai HL (2004) Estimation of PAHs dry deposition and $\mathrm{BaP}$ toxic equivalency factors (TEFs) study at urban, industry park and rural sampling sites in central Taiwan, Taichung. Chemosphere 55:787-796

Furumai H, Baimer H, Boller M (2002) Dynamic behavior of suspended pollutions and particle size distribution in the highway runoff. Water Sci Technol 46:413-418

Gan HY, Zhou MN, Li DQ, Zhou YZ (2008) Quality characterization and impact assessment of highway runoff in urban and rural area of Guangzhou, China. Environ Monit Assess 140(1-3):147-159

Gastaldini MCC, Silva ARV (2013) Pollutant distribution on urban surfaces: case study in southern Brazil. J Environ Eng 139(2):269-276

Gilbert JK, Clausen JC (2006) Stormwater runoff quality and quantity from asphalt, paver, and crushed stone driveways in Connecticut. Water Res 40:826-832

Goonetilleke A, Egodawatta P, Kitchen B (2009) Evaluation of pollutant build-up and wash-off from selected land uses at the Port of Brisbane, Australia. Mar Pollut Bull 58(2):213-221

Gromaire MC, Garnaud S, Gonzalez A, Chebbo G (1999) Characterization of Urban Runoff Pollution in Paris. Water Sci Technol 39(2):1-8 
Ha SY, Kim GB, Yim UH, Shim WJ, Hong SH, Han GM (2012) Particlesize distribution of polycyclic aromatic hydrocarbons in urban road dust of Masan, Korea. Arch Environ Contam Toxicol 63(2): 189-198

Han YH, Lau SL, Kayhanian M, Stenstrom MK (2006) Characteristics of highway stormwater runoff. Water Environ Res 78(12):2377-2388

Herngren L, Goonetilleke A, Ayoko GA (2005) Understanding heavy metal and suspended solids relationships in urban stormwater using simulated rainfall. J Environ Manag 78:149-158

Hou PQ (2012) Research on the pollution characteristics and influencing factors of urban roof runoff and road runoff [D]. Research Centre for Eco-Environmental Sciences. University of Chinese Academy of Sciences, Beijing

Huang J, Du PF, Ao CT, Lei MH, Zhang DQ, Ho MH, Wang ZS (2007) Characterization of surface runoff from a subtropics urban catchment. J Environ Sci 19(2):148-152

Jing HW, Hua L, Sun CH, Guo J (2008) Analysis on urban lakes' eutrophication status in Beijing. J Lake Sci 30(3):357-363 (in Chinese)

Lee JH, Bang KW (2000) Characterisation of urban stormwater runoff. Water Res 34(6):1773-1780

Lee JY, Bak G, Han M (2012) Quality of roof-harvested rainwater comparison of different roofing materials. Environ Pollut 162: 422-429

Li LQ, Yin CQ, He QC, Kong LL (2007) First flush of storm runoff pollution from an urban catchment in China. J Environ Sci 19: 295-299

Liu XJ, Ju XT, Zhang Y, He C, Kopsch J, Fusuo Z (2006) Nitrogen deposition in agroecosystems in the Beijing area. Agric Ecosyst Environ 113:370-377

Liu A, Egodawatta P, Guan YT et al (2013) Influence of rainfall and catchment characteristics on urban stormwater quality. Sci Total Environ 444:255-262

Maniquiz MC, Lee S, Lee E, Kim L (2009) Development of linear regression model for metals from transportation land uses. Water Sci Technol 59(12):2495-2501

Miguntanna NP, Liu A, Egodawatta P, Goonetilleke A (2013) Characterising nutrients wash-off for effective urban stormwater treatment design. J Environ Manag 120:61-67

Murakami M, Nakajima F, Furumai H (2005) Size- and densitydistributions and sources of polycyclic aromatic hydrocarbons in urban road dust. Chemosphere 61(6):783-791

Novotny V, Witte JW (1997) Ascertaining aquatic ecological risks of urban stormwater discharges. Water Res 31(10):2573-2585

Opher T, Friedler E (2010) Factors affecting highway runoff quality. Urban Water J 7(3):155-172

Pitte R, Morquecho R (2005) Stormwater quality as described in the National Stormwater Quality Database (NSQD). 10th International Conference on Urban Drainage. Copenhagen/Denmark: 21-26
Ren YF, Wang XK, Ouyang ZY, Zheng H, Duan XM, Miao H (2008) Stormwater runoff quality from different surfaces in an urban catchment in Beijing, China. Water Environ Res 80(8):719-724

Roberts AD, Prince SD, Jantz CA, Goetz SJ (2009) Effects of projected future urban land cover on nitrogen and phosphorus runoff to Chesapeake Bay. Ecol Eng 35:1758-1772

Roger S, Montrejaud-vignoles M, Andral MC, Herremans L, Fortune JP (1998) Mineral, physical and chemical analysis of the solid matter carried by motorway runoff water. Water Res 32:1119-1125

Sansalone JJ, Buchberger S (1995) An infiltration device as a best management practice for immobilizing heavy metals in urban highway runoff. Water Sci Technol 32(4):119-125

Sansalone JJ, Buchberger SG (1997) Partitioning and first flush of metals in urban roadway storm water. J Environ Eng 123:134-143

Sansalone JJ, Kim JY (2008) Transport of particulate matter fractions in urban source area pavement surface runoff. J Environ Qual 37(5): $1883-1893$

Schiff KC, Tiefenthaler LL (2011) Seasonal flushing of pollutant concentrations and loads in urban stormwater 1. J Am Water Resour Assoc 47(1):136-142

Sheng Y, Ying G, Sansalone J (2008) Differentiation of transport for particulate and dissolved water chemistry load indices in rainfall-runoff from urban source area water-sheds. J Hydrol 361:144-158

State Environmental Protection Agency of China (1989) Water and Wastewater Monitoring and Analyzing Method, 3rd edn. China Environmental Science Press, Beijing, China

Taylor GD, Fletcher TD, Wong THF, Breen PF, Duncan HP (2005) Nitrogen composition in urban runoff: implications for stormwater management. Water Res 39(10):1982-1989

Vaze J, Chiew FHS (2002) Experimental study of pollutant accumulation on an urban road surface. Urban Water 4:378-389

Vaze J, Chiew FHS (2004) Nutrient load associated with different sediment sizes in the urban stormwater and surface pollutions. J Environ Eng 30:391-396

Wang X, Li JQ, Li YX, Shen ZY, Wang X, Yang ZF, Lou IC (2014) Is urban development an urban river killer? A case study of Yongding Diversion Channel in Beijing, China. J Environ Sci China 26(6): 1232-1237

Zhao HT, Li XY, Wang XM, Tain D (2010) Grain size distribution of road-deposited sediment and its contribution to heavy metal pollution in urban runoff in Beijing, China. J Hazard Mater 183(1-3): 203-210

Zhou D, Bi CJ, Chen ZL, Yu ZJ, Wang J, Han JC (2013) Phosphorus loads from different urban storm runoff sources in southern China: a case study in Wenzhou City. Environ Sci Pollut Res Int 20(11): $8227-8236$ 